\title{
Characteristics of a New Device for Intubation Through a Laryngeal Mask Airway Over a Flexible Endoscope
}

\author{
Vernon H Vivian (D) \\ Tyson L Pardon ${ }^{2}$ \\ Samuel Vivian ${ }^{3}$ \\ André Van Zundert (D) ${ }^{4,5}$ \\ 'Department of Anaesthesiology, Gympie \\ General Hospital, Sunshine Coast, QLD, \\ Australia; ${ }^{2}$ Emergency Department, \\ Sunshine Cost Health Services, Sunshine \\ Coast, QLD, Australia; ${ }^{3}$ Prehospital EMS, \\ Queensland Ambulance Services, \\ Brisbane, QLD, Australia; ${ }^{4}$ Department \\ of Anesthesiology, Royal Brisbane \& \\ Women's Hospital, Brisbane, Australia; \\ ${ }^{5}$ The University of Queensland, Brisbane, \\ QLD, Australia
}

Correspondence: Vernon H Vivian Email vjcsviv@hotmail.com

\begin{abstract}
The laryngeal mask airway (LMA) is widely used for airway management in the emergency and elective treatment of patients in both the in-hospital and prehospital setting. The rate of prehospital use is increasing. The LMA is a vital link in the vortex approach to managing a difficult airway. Clinicians will be increasingly faced with the dilemma of managing the patient who has an LMA in place, but still requires the airway secured by an endotracheal tube (ETT). Flexible endoscopic intubation through an LMA is a simpler procedure than awake flexible endoscopic intubation. Furthermore, intubating flexible endoscopes are increasingly available and affordable (now single use) making its use out of the domains of the operating theater and intensive care unit feasible. The authors aim to inform clinicians about the indications, physical characteristics, and insertion/removal techniques related to a new device, the Rescue ${ }^{\mathrm{TM}}$ ETT (Genesis Airway Innovations ${ }^{\circledR}$, Sunshine Coast, Australia), designed specifically for intubation through an LMA over a flexible endoscope and compare them to current devices used for this purpose.
\end{abstract}

Keywords: laryngeal mask airway, intubation, fiberoptic, emergency, airway, scope, vortex

\section{Introduction}

Archie Brain introduced the laryngeal mask airway, ie, LMA-Classic in $1987 .^{1}$ Soon, the need for an LMA to be used as an intubation conduit for endotracheal intubation was recognized. The LMA-Classic was unsuitable, the airway tube was too narrow and too long to allow the endotracheal tube (ETT) to be reliably placed distal to the vocal cords, and it was subsequently difficult to remove the LMA over the ETT after tracheal intubation. In recognition of the importance of securing the airway with an ETT after placement of an LMA, a decade later in 1997, Brain produced the intubating LMA and a specific endotracheal tube, ${ }^{2}$ the LMA-Fastrach TM and Fastrach ${ }^{\text {TM }}$ ETT (both Teleflex ${ }^{\circledR}$, Westmeath, Ireland). Since then, multiple laryngeal mask airways dedicated for this purpose have been produced (Ambu AuraGain ${ }^{\mathrm{TM}}$ Air-Q ${ }^{\mathrm{TM}}, \mathrm{C}$ Trach $^{\mathrm{TM}}$, and Unique Evo $\left.{ }^{\mathrm{TM}}\right)$, the evolution of the LMA has been eloquently described by Sorbello in "Evolution of the supraglottic airway devices: the Darwinian perspective." ${ }^{3}$ The Fastrach ${ }^{\mathrm{TM}}$ ETT designed by Brain remains the only widely commercially available ETT designed for intubation through an LMA. The development of the ETT used to intubate through an LMA may have been neglected and needs to be subjected to the same evolutionary pressures. 
Intubation through an LMA over a flexible endoscope in a modified Baileys maneuver ${ }^{4}$ is gaining acceptance as a primary technique when poor tolerance to apnea is expected. Clinicians will be increasingly faced with the dilemma (Table 1) of managing the patient who has an LMA in place, but still requires the airway secured by an ETT.

\section{The Ideal Characteristics of an Endotracheal Tube to Intubate Through an LMA Over a Flexible Endoscope}

When Brain was designing the ETT to be compatible with the intubating LMA, a major concern was the angle at which the ETT exited from the LMA mask aperture so that it lined up with the vocal cords and trachea to assist in blind intubation. The ideal tube was found to be a straight, soft wire reinforced, silicone ETT with a soft conical Tuohy-like tip - the Fastrach ${ }^{\mathrm{TM}}$ ETT (Teleflex ${ }^{\circledR}$, Westmeath, Ireland).

Although blind intubation through a laryngeal mask airway is feasible to reduce trauma to the larynx and increase first pass intubation, using a flexible endoscope to achieve endotracheal intubation is currently recommended. ${ }^{5,6}$

In the design of an ETT suitable for intubation over a flexible endoscope through an LMA, the following characteristics were considered important:

Table I A Comparison of Two Current Devices i.e., the Fastrach ETT ${ }^{\mathrm{TM}}$ and Aintree Intubating Catheter ${ }^{\mathrm{TM}}$ (AIC) and the Rescue

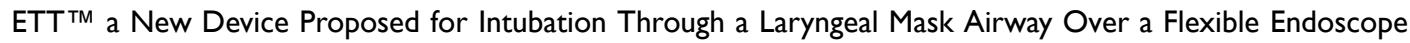

\begin{tabular}{|c|c|c|c|}
\hline & Fastrach $^{\mathrm{TM}}$ ETT & $\begin{array}{l}\text { Aintree Intubation } \\
\text { Catheter }^{\mathrm{TM}}\end{array}$ & Rescue $^{\mathrm{TM}}$ ETT \\
\hline $\begin{array}{l}\text { Design of tip/bevel to assist } \\
\text { successful first pass intubation }\end{array}$ & Conical Tuohy-like tip & $\mathrm{n} / \mathrm{a}$ & $\begin{array}{l}\text { Posterior facing bevel + curved } \\
\text { hemispheric tip }\end{array}$ \\
\hline Length of device & $\begin{array}{c}25 \mathrm{~cm} \\
\text { ETT sizes } 8,7.5 \text {, and } \\
7 \mathrm{~mm} \text { measure } 25 \mathrm{~cm} \\
\text { to upper border of cuff }\end{array}$ & $56 \mathrm{~cm}$ & $\begin{array}{c}\text { ETT sizes } 5.5 \text { to } 9 \mathrm{mml} \\
7 \text { to } 8.5 \mathrm{~mm} \\
\text { measure } 25 \mathrm{~cm} \text { to upper border } \\
\text { of cuff }\end{array}$ \\
\hline Material used for manufacture & $\begin{array}{l}\text { Wire reinforced silicone and } \\
\text { PVC. } \\
\text { Soft and malleable }\end{array}$ & $\begin{array}{c}\text { Polyethylene } \\
\text { Semi-rigid *Haemorrhage, } \\
\text { pneumothorax, mediastinitis and } \\
\text { deaths, have all been reported } \\
\text { with the use of airway exchange } \\
\text { catheters. }{ }^{16,17}\end{array}$ & $\begin{array}{l}\text { PVC and wire reinforced PVC. } \\
\text { Soft and malleable }\end{array}$ \\
\hline $\begin{array}{l}\text { Ease of removal of the LMA over } \\
\text { the ETT }\end{array}$ & $\begin{array}{l}\text { Withdrawn over solid stabilizer } \\
\text { rod - danger of tube migrating/ } \\
\text { extubation. } \\
\text { FOB needs to be reintroduced to } \\
\text { verify position of ETT. }\end{array}$ & $\begin{array}{c}\text { Easily withdrawn over narrow } \\
\text { diameter AIC }\end{array}$ & $\begin{array}{l}\text { Withdrawn over airway tube } \\
\text { connected to ETT. Continued } \\
\text { ventilation. FOB only removed } \\
\text { after LMA is withdrawn, allowing } \\
\text { ETT position to be verified. }\end{array}$ \\
\hline Continuous ventilation possible & $\begin{array}{l}\text { No } \\
\text { Interruption occurs when LMA is } \\
\text { withdrawn over ETT + solid } \\
\text { stabilizer rod }\end{array}$ & $\begin{array}{l}\text { Ventilation through AIC only } \\
\text { recommended when oxygen } \\
\text { requirements are high due to the } \\
\text { risk of barotrauma }\end{array}$ & Yes \\
\hline Suitable long-term intubation & $\begin{array}{c}\text { No } \\
\text { - Low volume high-pressure cuff } \\
\text { - Wire reinforced ETT }\end{array}$ & $n / a$ & $\begin{array}{c}\text { Yes } \\
\text { - ETT available in PVC } \\
\text { - High-volume low-pressure cuff }\end{array}$ \\
\hline Interruption to airway security & $\begin{array}{c}\text { Nil } \\
\text { Achieved with an LMA and then } \\
\text { an ETT }\end{array}$ & $\begin{array}{l}\text { Yes } \\
\text { After the LMA is withdrawn over } \\
\text { the AIC the airway is not secure } \\
\text { until the ETT is railroaded over } \\
\text { the AIC }\end{array}$ & $\begin{array}{l}\text { Nil } \\
\text { Achieved with an LMA and then } \\
\text { an ETT }\end{array}$ \\
\hline
\end{tabular}




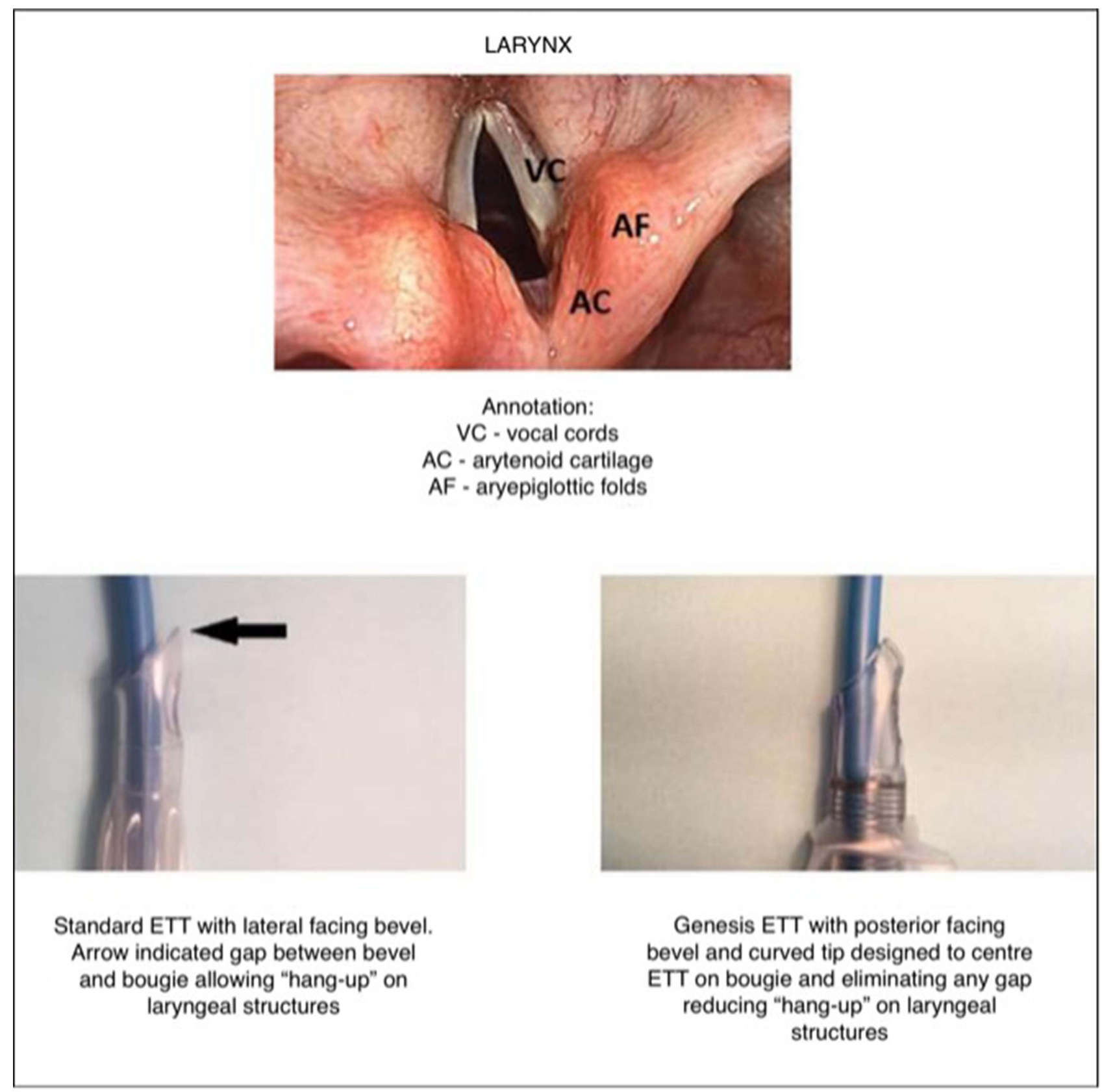

Figure I Comparison of the bevels of a standard ETT with lateral facing bevel (left) and Rescue TM ETT (right) to illustrate the mechanisms to reduce laryngeal "hang-up". Notes: A bougie is photographed inside the lumen of the ETTs to simulate the similar mechanism that occurs with a flexible endoscope.

- The tip and bevel must be suitable for first pass successful intubation. Hang-up (Figure 1) may occur at the level of the arytenoids/aryepiglottic folds, or on the anterior tracheal wall. ${ }^{7}$ Studies suggest that a posterior facing bevel, ${ }^{8-11}$ conical or hemispheric shapes $^{12}$ as well as a softer tip are superior. ${ }^{12}$ When using an ETT with a lateral facing bevel rotating the tube 90 degrees in an anticlockwise direction (the bevel becomes posterior facing) relieves the hang-up but may cause significant trauma and even complete airway obstruction in awake patients. ${ }^{13}$ For this reason many clinicians recommend the 90-degree anticlockwise rotation of the endotracheal tube before intubation is attempted.

- The length of the ETT needs to be sufficient to be placed below the cords proximal to the carina. Standard ETTs are unsuitable. The shaft length of most laryngeal mask airways sizes numbers 3 to 5 
is 19-20 cm. The distance from the airway tube aperture in the mask to the vocal cords varies from 2 to $4.7 \mathrm{~cm}$ in adults. ${ }^{14}$ For the lower border of the ETT cuff to be $2 \mathrm{~cm}$ below the vocal cords, the length of the ETT to the proximal border of the cuff should be $20+4.7+2=26.4 \mathrm{~cm}$. A preformed nasal RAE and a microlaryngeal ETT are longer than standard oral ETTs and have been advocated for intubation through a laryngeal mask airway. ${ }^{15}$

- The ETT is preferably manufactured from a soft material (eg, silicone). A softer ETT reduces trauma to the larynx and trachea and allows the tube to conform to the flexible endoscope reducing hang-up particularly at the anterior tracheal wall. ${ }^{11,12}$

- The LMA must be easily withdrawn over the ETT.

- The $15 \mathrm{~mm}$ connector for the ETT must be detachable.

- Continued airway security with minimal interruption to ventilation and oxygenation for the duration of the procedure is vital.

- The technique should be simple with minimal steps to the procedure, easy to learn and perform without regular practice.

- The ability to verify ETT position with the flexible endoscope until after the laryngeal mask airway is withdrawn would be advantageous.

- The ETT should be suitable for long-term intubation with a high-volume low-pressure cuff manufactured from polyvinyl chloride (PVC) without wire reinforcing.

- The device should be affordable to allow regular practice and universal availability.

\section{Discussion}

\section{Internal Diameter (ID) of ETT that May} be Used

The ID of the Rescue ${ }^{\mathrm{TM}}$ and Fastrach ${ }^{\mathrm{TM}}$ ETT (see Table 1) is limited to a maximum of $8 \mathrm{~mm}$ with passage through an airway tube of an LMA. Evidence suggests that with current ventilators smaller ID ETTs are adequate, ${ }^{18}$ except for critically ill patients requiring long-term intubation when an $8 \mathrm{~mm}$ ID ETT for women and a $9 \mathrm{~mm}$ ID ETT for men is required. The use of large diameter ETTs can cause trauma to the larynx and trachea. ${ }^{18}$ When using an Aintree Intubation Catheter (AIC) an ETT larger than $8 \mathrm{~mm}$ ID may be used, however, $7 \mathrm{~mm}$ is the minimum ID that fits over an AIC, limiting its use in pediatric patients. The Rescue ${ }^{\mathrm{TM}}$ ETT is available from ID size 5.5 to size $8 \mathrm{~mm}$ and the Fastrach $\mathrm{ETT}^{\mathrm{TM}}$ in size 6 to size $8 \mathrm{~mm}$ allowing use both in pediatric patients and adults.

\section{Limitations Related to the Length of the Devices}

A size $8 \mathrm{~mm}$ ID Fastrach ${ }^{\mathrm{TM}}$ ETT measures $25 \mathrm{~cm}$ from the proximal end of the tube to the upper border of the cuff. An i-gel ${ }^{\mathrm{TM}}$ laryngeal mask airway (size 5) as an airway tube of $20 \mathrm{~cm}$, in a tall patient add $4.7 \mathrm{~cm}^{14}$ for the distance between the aperture in the mask to the vocal cords makes $24.7 \mathrm{~cm}$. This makes the Fastrach ${ }^{\mathrm{TM}}$ ETT too short to be reliably placed below the vocal cords in the trachea. The Rescue ${ }^{\mathrm{TM}}$ ETT (Figure 2A) when combined with the airway tubing has a minimal length of $34 \mathrm{~cm}$ (Figure 3 ) to the upper border of the cuff allowing it to be placed at an adequate depth even with an extremely tall patient, The AIC length $(56 \mathrm{~cm})$ may be too short to railroad an ETT over in very tall patients. ${ }^{19}$

B

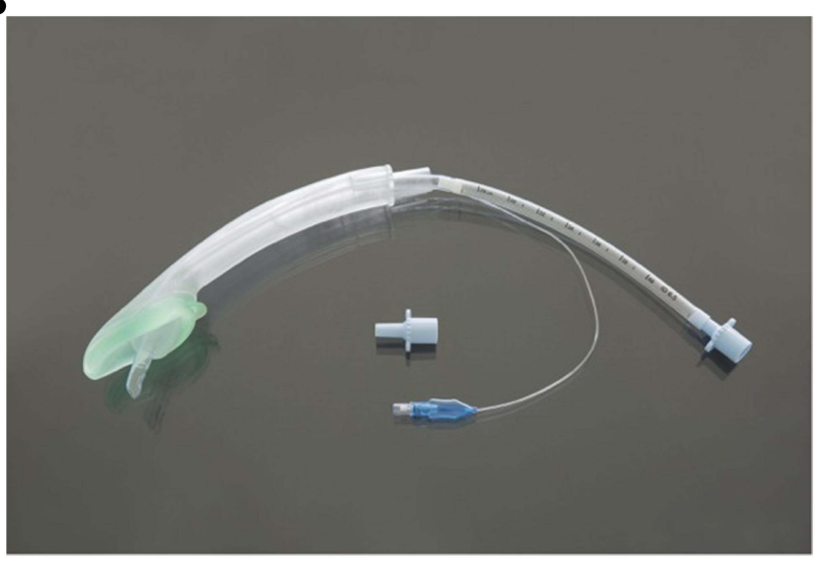

Figure 2 (A) Components of the Rescue ${ }^{\mathrm{TM}}{ }^{\mathrm{TM}}$ ETT (PVC). (A) Airway tubing. (B) $15 \mathrm{~mm}$ ISO connector. (C) ETT with posterior-facing bevel. (B) THE RESCUE ${ }^{\mathrm{TM}}$ ETT inserted through an I-GEL ${ }^{\mathrm{TM}}$ laryngeal mask airway. 


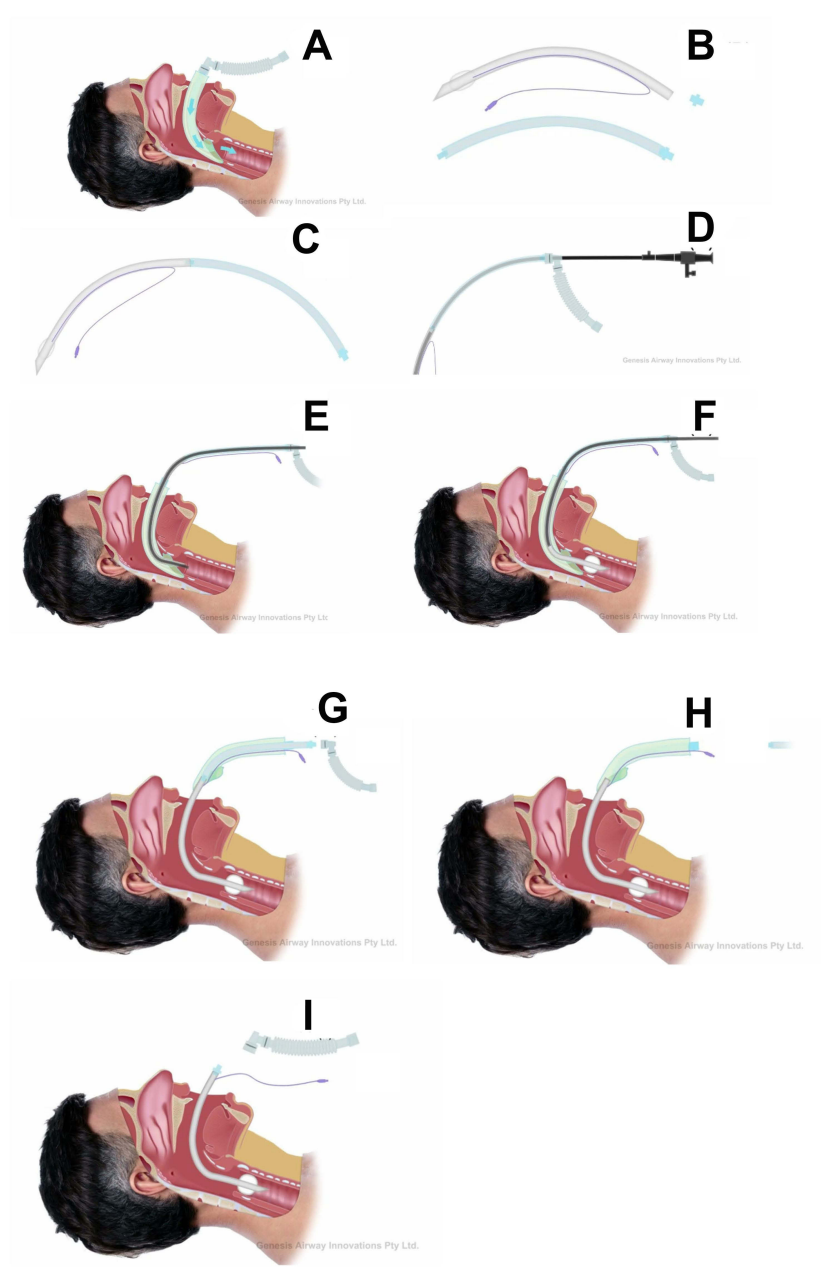

Figure 3 A schematic diagram to demonstrate the method of inserting the Rescue ${ }^{\mathrm{TM}}$ ETT through an i-gel ${ }^{\mathrm{TM}}$ laryngeal mask airway.

Notes: Rescue TM ETT; A method of use with a flexible endoscope. (A) An LMA is used to secure the airway. (B) An appropriately sized Rescue ${ }^{T M}$ ETT is selected (the ETT selected must not be forced through the shaft of the LMA as damage to the cuff of the ETT may occur). (C) The $15 \mathrm{~mm}$ ISO connector is removed from the ETT and is connected to the airway tubing. The proximal end of the ETT and cuff is well lubricated. (D) A self-sealing connector with a sidearm is placed over the $15 \mathrm{~mm}$ connector of the airway tubing. An intubating flexible endoscope with a working length of at least $60 \mathrm{~cm}$ and sufficient diameter to abut against the curved atraumatic tip of the ETT is chosen. This complex is then loaded over the endoscope with the endoscope tip just proximal to the tip of the ETT. (E) The LMA is disconnected. The ETT/airway tube is then connected to the anesthetic machine and the distal ETT inserted into the shaft of the LMA. The cuff of the ETT is inflated in the shaft of the LMA once the ETT tube tip is $2 \mathrm{~cm}$ out of the distal LMA aperture allowing continued ventilation. (F) The flexible endoscope is then advanced through the vocal cords and into the trachea. The cuff of the ETT is deflated and the ETT/airway tubing is railroaded over the endoscope until the cuff of the ETT is a safe distance below the vocal cords and the cuff is reinflated. (G) The ETT/airway tubing is stabilized. The LMA cuff is deflated, and it is withdrawn carefully over the ETT/airway tube. $(\mathbf{H})$ The ETT and airway tube are disconnected, and the airway tube is removed from the shaft of the LMA and then the inflation line, pilot balloon and inflation valve are delivered through the shaft of the LMA. (I) The $15 \mathrm{~mm}$ connector is inserted into the proximal ETT tubing, and the patient is connected to the ventilator.

\section{Safety Concerns with the AIC}

The AIC is an airway exchange catheter (AEC), which is often recommended for intubation over an FOB. Of concern is the safety profile. The literature shows that these products can have a high rate of complications, as high as $60 \%{ }^{20-22}$ Pneumothorax, which can occur in up to $11 \%,{ }^{23}$ is a known complication of high-pressure jet ventilation as a result of barotrauma, auto-PEEP, and dynamic hyperinflation. However, pneumothorax has been reported with the use of an AEC without high-pressure jet ventilation. ${ }^{24,25}$

We suggest that AEC should only be used by teams that are versatile and trained in their use.

\section{Potential of Uncoupling While Using the Rescue $^{\text {TM }}$ ETT}

A potential concern with the Rescue ${ }^{\mathrm{TM}}$ ETT is the airway tube and ETT uncoupling in the procedure (Figures 2A and $\mathrm{B}$ ), however, the forces applied while intubating and then withdrawing the LMA over the ETT/airway complex, act to keep this coupling together.

\section{Ability to Maintain Ventilation}

When using the Rescue ${ }^{\mathrm{TM}}$ ETT (Figure 3) a self-sealing connector with a sidearm placed over the $15 \mathrm{~mm}$ connector of the airway tubing that is joined to the ETT. The flexible endoscope is then inserted through the complex with the tip of the endoscope just proximal to the end of the ETT. The sidearm of the self-sealing connector is then attached to a ventilator. The lubricated cuff of the ETT usually forms an adequate seal with the airway tube of the LMA to allow continuous ventilation while the trachea is intubated, alternatively if the seal is not adequate once the tip of the endoscope is just out of the laryngeal mask airway tube the cuff of the ETT may be inflated in the airway tube of the LMA and ventilation commenced with the cuff being deflated before the ETT is railroaded over the endoscope into the trachea. While withdrawing the LMA ventilation is continued, and the flexible endoscope is left in place until the LMA is fully withdrawn to confirm the ETT remains placed at the correct depth.

The Fastrach ${ }^{\mathrm{TM}}$ ETT requires an interruption to ventilation while the laryngeal mask airway is withdrawn over a solid stabilizer rod and then a repeat scope to confirm that the ETT has not migrated.

\section{Conclusion}

On review of the literature, it is abundantly obvious that an ETT with a posterior-facing bevel and curved or tapered tip to center the tube on the scope and reduce hang-up is ideal for intubation over a flexible endoscope and that the use of the current standard ETT with a lateral-facing bevel should be discouraged. 
The newly described Rescue ${ }^{\mathrm{TM}}$ ETT is a simple and safe device deployed with a simple technique. The Rescue ${ }^{\mathrm{TM}}$ ETT retains all the advantages of the Fastrach ${ }^{\mathrm{TM}}$ ETT and as demonstrated in this article, offers several advantages over both the Fastrach ${ }^{\mathrm{TM}}$ ETT and the Aintree Intubation Catheter ${ }^{\mathrm{TM}}$. A clinical study is required to verify these claims before being introduced into clinical practice.

\section{Author Contributions}

All authors made a significant contribution to the work reported, whether that is in the conception, study design, execution, acquisition of data, analysis and interpretation, or in all these areas; took part in drafting, revising or critically reviewing the article; gave final approval of the version to be published; have agreed on the journal to which the article has been submitted; and agree to be accountable for all aspects of the work.

\section{Funding}

This research did not receive any specific grant from funding agencies in the public, commercial; or not-forprofit sectors.

\section{Disclosure}

Vernon $\mathrm{H}$ Vivian is a director of Genesis Airway Innovations Pty Ltd that holds the patents on these devices. André Van Zundert, Tyson L Pardon and Samuel Vivian report no conflicts of interest in this work.

\section{References}

1. Van Zundert TCR, Brimacombe JR, Ferson DZ, Bacon DR, Wilkins DJ. Archie Brain: celebrating 30 years of development in laryngeal mask airways on. Anaesthesia. 2012;67:1375-1385. doi:10.1111/anae.12003.x

2. Brain AI, Verghese C, Addy EV, Kapila A. The intubating laryngeal mask: development of a new device for intubation of the trachea. $\mathrm{Br}$ J Anaesth. 1997;79:699-703. doi:10.1093/bja/79.6.699

3. Sorbello M. Evolution of the supraglottic airway: the Darwinian perspective. Minerva Anestesiol. 2018;84:699-703.

4. Sorbello M, Cortese G, Gaconnet C, Skinner M. A modified Bailey's manoeuvre for supraglottic airway continuum using LMA protector ${ }^{\mathrm{TM}}$. Indian J Anaesth. 2019;63:78-80. doi:10.4103/ija.IJA_502_18

5. Noppens RR, Pius J. Blind intubation using supraglottic devices: why should we even try? Can J Anaesth. 2019;66:629-632. doi:10.1007/ s12630-019-01352-5

6. Higgs A, McGrath BA, Goddard C, Rangasami J, Suntharalingam G, Gale R. Cook TM, and on behalf of the Difficult Airway Society, Intensive Care Society, Faculty of Intensive Care Medicine, Royal College of Anaesthetists: guidelines for the management of tracheal intubation in critically ill adults. Br J Anaesth. 2018;120:323-352.

7. Johnson DM, From AM, Smith RB, From RP, Maktabi MA. Endoscopic Study of mechanisms of failure of endotracheal tube advancement into the trachea during awake fibreoptic orotracheal intubation. Anesthesiology. 2005;102:910-914. doi:10.1097/00000 542-200505000-00008
8. Jafari A, Gharaei B, Reza Kamranmanesh M, et al. Wire reinforced endotracheal tube compared with parker flex-tip tube for oral fibre optic intubation: a randomised clinical trial. Minerva Anestesiol. 2014;80:324-329.

9. Bararka A, Rizk M, Muallem M, Bizri SH, Ayoub C. Posteriorbeveled vs lateral-beveled tracheal tube for fiber optic intubation. Can J Anaesth. 2002;49:889-890. doi:10.1007/BF03017434

10. Ho A, Mizubuti G. Tracheal intubation: the proof is in the bevel. $J$ Emerg Med. 2018;55:821-826. doi:10.1016/j.jemermed.20 18.09.001

11. Su K, Gao X, Xue FS, Ding GN, Zhang Y, Tian M. Difficult tracheal tube passage and subglottic airway injury during intubation with the Glidescope video laryngoscope: a randomised, controlled comparison of three tracheal tubes. Anaesthesia. 2017;72:504-511. doi:10.1111/ anae. 13755

12. Ruari Greer J, Smith SP, Strang T. A comparison of tracheal tube tip designs on the passage of an endotracheal tube during oral fibreoptic intubation. Anesthesiology. 2001;94:729-731. doi:10.1097/000005 42-200105000-00007

13. Sato S, Asai T, Hashimoto Y, Arai T, Okuda Y. Airway obstruction during attempts at fibreoptic intubation in an awake patient. Masui. 2014;63:548-551.

14. Pennant JH, Joshi GP. Intubation through the laryngeal mask airway. Anesthesiology. 1995;83:891-892. doi:10.1097/00000542-1995100 00-00048

15. Preis CA, Pries IS. Oversize endotracheal tubes and intubation via laryngeal mask airway. Anesthesiology. 1997;87:187. doi:10.1097/ 00000542-199707000-00044

16. Henninger A, Krueger WA, Dieteric HJ, Konigsrainer I, Schroeder TH. Complications using a hollow fibre airway exchange catheter for tracheal tube exchange in critically ill patients. Acta Anaesthesiol Scand. 2008;52:1031. doi:10.1111/j.1399-6576.2008.01 686.x

17. Evans H, Hodzovic I, Latto IP. Tracheal tube introducers: choose and use with care. Anaesthesia. 2010;65:859. doi:10.1111/j.13652044.2010.06432.x

18. Farrow S, Farrow C, Soni N. Size matters: choosing the right tracheal tube. Anaesthesia. 2012;67:815-819. doi:10.1111/j.1365-2044.2012. 07250.x

19. Gruenbaum SE, Gruenbaum BF, Tsaregorodtsev S, Dubilet M, Melamed I, Zlotnik A. Novel use of an exchange catheter to facilitate intubation with an aintree catheter in a tall patient with a predicted difficult airway: a case report. J Med Case Rep. 2012;6(1):1-5.

20. Benumof JL. Airway exchange catheters: simple concept, potentially great danger. Anesthesiology. 1999;91:342-344. doi:10.1097/00000 542-199908000-00005

21. Baraka AS. Tension pneumothorax complicating jet ventilation via a cook airway exchange catheter. Anaesthesiology. 1999;91:557-558. doi:10.1097/00000542-199908000-00031

22. Mort TC. Continuous airway access for the difficult extubation: the efficacy of the airway exchange catheter. Anesth Analg. 2007;105:1357-1362. doi:10.1213/01.ane.0000282826.68646.a1

23. Cooper RM. The use of an endotracheal ventilation catheter in the management of difficult extubation. Can J Anaesth. 1996;43:90-93. doi:10.1007/BF03015965

24. Harris K, Chalhoub M, Maroun R, Elsayegh D. Endotracheal tube exchangers: should we look for safer alternatives. Heart Lung. 2012;41:67-69. doi:10.1016/j.hrtlng.2011.06.005

25. Duggan LV, Law JA, Murphy MF. Supplementing oxygen through an airway exchange catheter: efficacy, complications, and recommendations. Can J Anaesth. 2011;58:560-568. doi:10.1007/ s12630-011-9488-4 


\section{Publish your work in this journal}

Medical Devices: Evidence and Research is an international, peerreviewed, open access journal that focuses on the evidence, technology, research, and expert opinion supporting the use and application of medical devices in the diagnosis, monitoring, treatment and management of clinical conditions and physiological processes. The identification of novel devices and optimal use of existing devices which will lead to improved clinical outcomes and more effective patient management and safety is a key feature of the journal. The manuscript management system is completely online and includes a very quick and fair peer-review system. Visit http:// www.dovepress.com/testimonials.php to read real quotes from published authors. 